\title{
Extent of protective or allergy-inducing effects in cats and dogs
}

\author{
Edyta Krzych-Fałta',A-D, Konrad Furmańczyk ${ }^{2, B-C}$, Barbara Piekarska ${ }^{3, A, F}$, Filip Raciborski, ${ }^{3, A, E}$, \\ Aneta Tomaszewska ${ }^{3, A, F}$, Artur Walkiewicz ${ }^{3, A, F}$, Piotr Samel-Kowalik ${ }^{3, A}$, Jacek Borowicz ${ }^{3, A, E}$, \\ Andrzej Namysłowski ${ }^{3, A, F}$, Bolesław Krzysztof Samoliński ${ }^{3, A, D, F}$
${ }^{1}$ Department of Environmental Hazard Prevention and Allergology, Faculty of Health Science, Medical University, Warsaw, Poland
${ }^{2}$ Chair of Applied Mathematics, Faculty of Applied Informatics and Mathematics, University of Life Sciences (SGGW), Warsaw, Poland
${ }^{3}$ Department of Environmental Hazard Prevention and Allergology, Faculty of Health Science, Medical University, Warsaw, Poland
A - Research concept and design, B - Collection and/or assembly of data, C - Data analysis and interpretation, $D$ - Writing the article, E - Critical revision of the article, $F$ - Final approval of article

Krzych-Fałta E, Furmańczyk K, Piekarska B, Raciborski F, Tomaszewska A, Walkiewicz A, Samel-Kowalik P, Borowicz J, Namysłowski A, Samoliński
BK. Extent of protective or allergy-inducing effects in cats and dogs. Ann Agric Environ Med. 2018; 25(2): 268-273. doi: 10.26444/aaem/80596

\begin{abstract}
Objective. The study aimed to assess the effect of fur-bearing pets, including cats and dogs, on the health of individuals with allergic conditions.

Materials and method. The study group comprised 18,617 individuals (16,562 from urban and 2,055 from rural areas). The tool used in the study was the European Community Respiratory Health Survey (ECRHS) and International Study of Asthma and Allergies in Childhood (ISAAC) study questionnaire, adapted to European conditions (Middle and Eastern Europe) and used as part of the study Implementation of a System for the Prevention and Early Detection of Allergic Diseases in Poland. Results. The factors determining the keeping of fur-bearing pets in a household included a larger living space and the number of cigarettes smoked, which were observed especially in urban settings. The keeping of fur-bearing animals in rural areas acts preventively against allergic conditions, while in urban areas, these animals were a factor clearly aggravating symptoms of bronchial asthma - the risk of cough (OR 1.921; $\mathrm{Cl} 10-3.36 ; \mathrm{P}=0.02)$ and wheezing $(\mathrm{OR} 2.60 ; \mathrm{Cl} 1.22-5.54 ; \mathrm{P}=0.01)$. Conclusion. Fur-bearing animals kept in rural settings exhibit preventive effects on the development of allergies; whereas in urban areas they exacerbate allergic symptoms, especially the symptoms of bronchial asthma.
\end{abstract}

\section{Key words}

allergic diseases, cat and dog allergens, risk factors

\section{INTRODUCTION}

Due to the high incidence reported, allergic conditions are a considerable challenge for modern medicine and public health. According to the World Allergy Organization data, approximately $40 \%$ of the general global population is affected by allergic conditions [1]. Polish studies conducted as part of the Epidemiology of Allergic Disorders in Poland (ECAP) study estimate that nearly $35 \%$ of the general Polish population are affected with an allergic disorder: $25 \%$ have allergic rhinitis, $5 \%$ - bronchial asthma (BA), $12 \%$ - asthma, $4 \%$ - dermatitis, and $2.1-6.7 \%$ of the Polish paediatric population have urticaria [2]. In view of a number of factors that contribute to an inflammatory reaction (outdoor and indoor pollutants, living conditions, socio-economic status, genetic factors, hygiene habits [3, 4], there has been an increasing interest in those factors which, on the one hand can have a protective effect, and on the other hand can predispose to the development of allergic conditions. One theory explaining the correlation between the effect of certain environmental factors and

\footnotetext{
Address for correspondence: Edyta Krzych-Fałta, Unit of Environmental Hazard Prevention and Allergology, Faculty of Health Science, Medical University of Warsaw, Banacha 1a, 02-097 Warszawa, Poland

E-mail: e.krzych@gmail.com

Received: 28.05.2017; accepted: 17.11.2017; first published: 11.12.2017
}

the prevalence of allergies is Strachan's hygiene hypothesis, which posits a preventive effect of exposure to infections and low hygiene [5], a protective effect of exposure to farm animals, microorganisms, or drinking non-pasteurized milk in early childhood $[6,7]$.

The seemingly simple allergy to fur-bearing animals raises some questions, especially in terms of the extent to which exposure to cat or dog allergens in early childhood protects against or predisposes to the development of allergic disorders. Allergens of fur-bearing animals are among the most potent allergens, year-round allergens which, due to their size of $2.5 \mu \mathrm{m}$ (Fel d1) [8] and continual stimulation, are highly predisposing to the development of BA.

\section{OBJECTIVE}

The study aimed to assess the effect of fur-bearing pets, including cats and dogs, on the health of individuals with allergic conditions.

\section{MATERIALS AND METHOD}

The study group comprised 18,617 subjects (with $n=16,562$ (89\%), residents of urban areas, and $n=2,055$ (11\%) residents 
of rural areas) in the following age groups: 6-7-year-olds $(\mathrm{n}=4,510(24 \%)), 13$-14-year-olds $(\mathrm{n}=4,721(25 \%))$, and 20 -44-year-olds $(n=9,386(51 \%))$. For the purposes of this study, the respondents were stratified into subgroups: BA $(\mathrm{n}=227)$, perennial allergic rhinitis $(\mathrm{PAR})(\mathrm{n}=725)$, seasonal allergic rhinitis (SAR) $(\mathrm{n}=660)$, and healthy controls $(\mathrm{HC})$ (volunteers) $(\mathrm{n}=2,403)$. The study group included 10,011 females (54\%) and 8,606 males (46\%), selected randomly from the Polish Resident ID Number (PESEL) registry at the the Ministry of Interior and Administration. The research tool used in the study was the European Community Respiratory Health Survey (ECRHS) and International Study of Asthma and Allergies in Childhood (ISAAC) study questionnaire, adapted to European conditions (Middle and Eastern Europe) and used as part of the Implementation of a System for the Prevention and Early Detection of Allergic Diseases in Poland study. The study was conducted in eight cities (Gdansk, Wroclaw, Poznan, Katowice, Krakow, Lublin, Bialystok, and Warsaw) and in rural areas (Krasnostawski county). It was a two-stage study, with the first stage involving subject qualification (22,500 respondents) based on the questionnaire with the use of a PDA (Personal Digital Assistant); the second stage included 7,000 outpatient respondents who underwent additional diagnostic tests: skin-prick tests (Alergopharma, 15 allergens: birch, grass/cereal, mugwort, hazel, alder, rye, and plantain pollens, cat and dog allergens, Dermatophagoides pteronysinus, Dermatophagoides fairnae, mould mix I (Alternaria tenuis, Botrytis cinerea, Cladosporium herbarum, Curvularialunata, Fusariummoniliforme, Helminthosporium), mould mix II (Aspergillus fumigatus, Mucormucedo, Penicillium notatum, Rhizopusnigricans, Serpulalacrymans, Pullulariapullulans), Cladosporium herbarium, histamine, and control), lung function test, and peak nasal inspiratory flow (PNIF). Clinical diagnoses of AR (including perennial $\mathrm{AR}$ and seasonal $\mathrm{AR}$ ) and $\mathrm{BA}$ were verified based on Allergic
Rhinitis and its Impact for Asthma (ARIA) and Global Initiative for Asthma (GINA) guidelines.

The study was approved by the Ethics Committee/ Institutional Review Board of Medical University in Warsaw (KB/206/2005) and by the Inspector General for Personal Data Protection.

Statistical analysis. Statistical analysis included calculation of the odds ratio (OR), 95\% confidence interval, and the Wald test. The variety in distributions of the living space and the number of cigarettes smoked in the urban and rural populations was evaluated via the Kolmogorov-Smirnov test. Additionally, the prevalence of allergies to individual allergens in the evaluated study groups (BA, SAR, PAR, $\mathrm{HC}$ ) was assessed. The $\mathrm{P}$ value of $<0.05$ was considered to be statistically significant. All computation was carried out with an $R$ package [8a].

\section{RESULTS}

Rates of households keeping fur-bearing animals in urban and rural populations. A considerably greater proportion of respondents keep a dog (Tab. 1-2). The majority of urban respondents declared that they allow their pets to enter their house/bedroom. Only a small percentage of respondents had had fur-bearing pets at age $<1$ year, with a somewhat greater percentage having such pets at age $<5$ years. The question about whether contact with a fur-bearing animal produces difficulty breathing was answered affirmatively by nearly half of the respondents. Wheezing, shortness of breath, and chest tightness were reported mostly by patients with BA. The most prevalent symptoms following cat/dog allergen exposure were itchy and watery eyes, which were reported considerably more often by respondents with BA.

Table 1. Factors/behaviours in the evaluated urban population

\begin{tabular}{|c|c|c|c|c|c|c|c|c|}
\hline & \multicolumn{2}{|c|}{ SAR $n=576$} & \multicolumn{2}{|c|}{ PAR $n=654$} & \multicolumn{2}{|c|}{ atopic BA n=197 } & \multicolumn{2}{|c|}{$\mathrm{HC} n=2107$} \\
\hline & $\mathrm{n}$ & $\%$ & $\mathrm{~N}$ & $\%$ & $\mathrm{n}$ & $\%$ & $\mathrm{n}$ & $\%$ \\
\hline Having a cat & 63 & 10.9 & 77 & 11.8 & 22 & 11.2 & 281 & 13.3 \\
\hline Cat entering the house & 61 & 96.8 & 77 & 100.0 & 22 & 100.0 & 270 & 96.1 \\
\hline Cat entering the bedroom & 55 & 87.3 & 71 & 92.2 & 450 & 95.5 & 249 & 88.6 \\
\hline Having a dog & 158 & 27.4 & 174 & 26.6 & 21 & 35.5 & 541 & 25.7 \\
\hline Dog entering the bedroom & 135 & 85.4 & 144 & 83.7 & 56 & 81.2 & 471 & 87.4 \\
\hline Having a cat at age $<1$ year & 41 & 7.1 & 46 & 7.0 & 17 & 8.6 & 189 & 9.0 \\
\hline Having a cat at age $1-4$ years & 79 & 13.7 & 73 & 11.2 & 27 & 13.7 & 294 & 14.0 \\
\hline Having a cat at age $5-15$ years & 106 & 18.4 & 121 & 18.5 & 35 & 17.8 & 388 & 18.4 \\
\hline Having a dog at age $<1$ year & 83 & 14.4 & 95 & 14.5 & 34 & 17.3 & 323 & 15.3 \\
\hline Having a dog at age $5-15$ years & 180 & 31.3 & 189 & 28.9 & 70 & 35.5 & 677 & 32.1 \\
\hline Do you experience cough when exposed to animals? & 319 & 55.4 & 383 & 58.6 & 104 & 52.8 & 1168 & 55.4 \\
\hline Do you experience wheezing when exposed to animals? & 24 & 4.2 & 54 & 8.3 & 34 & 17.3 & 23 & 1.1 \\
\hline Do you experience chest tightness when exposed to animals? & 42 & 2.3 & 26 & 4.0 & 21 & 10.7 & 6 & 0.3 \\
\hline Do you experience shortness of breath when exposed to animals? & 13 & 1.7 & 8 & 1.2 & 12 & 6.1 & 3 & 0.1 \\
\hline Do you experience nasal congestion when exposed to animals? & 9 & 1.6 & 21 & 3.2 & 14 & 7.1 & 3 & 0.1 \\
\hline Do you experience itchy or watery eyes when exposed to animals? & 91 & 15.8 & 124 & 19.0 & 56 & 28.4 & 51 & 2.4 \\
\hline
\end{tabular}

BA bronchial asthma; HC - healthy controls; PAR - perennial allergic rhinitis; SAR - seasonal allergic rhinitis 
Table 2. Factors/behaviours in the evaluated rural population

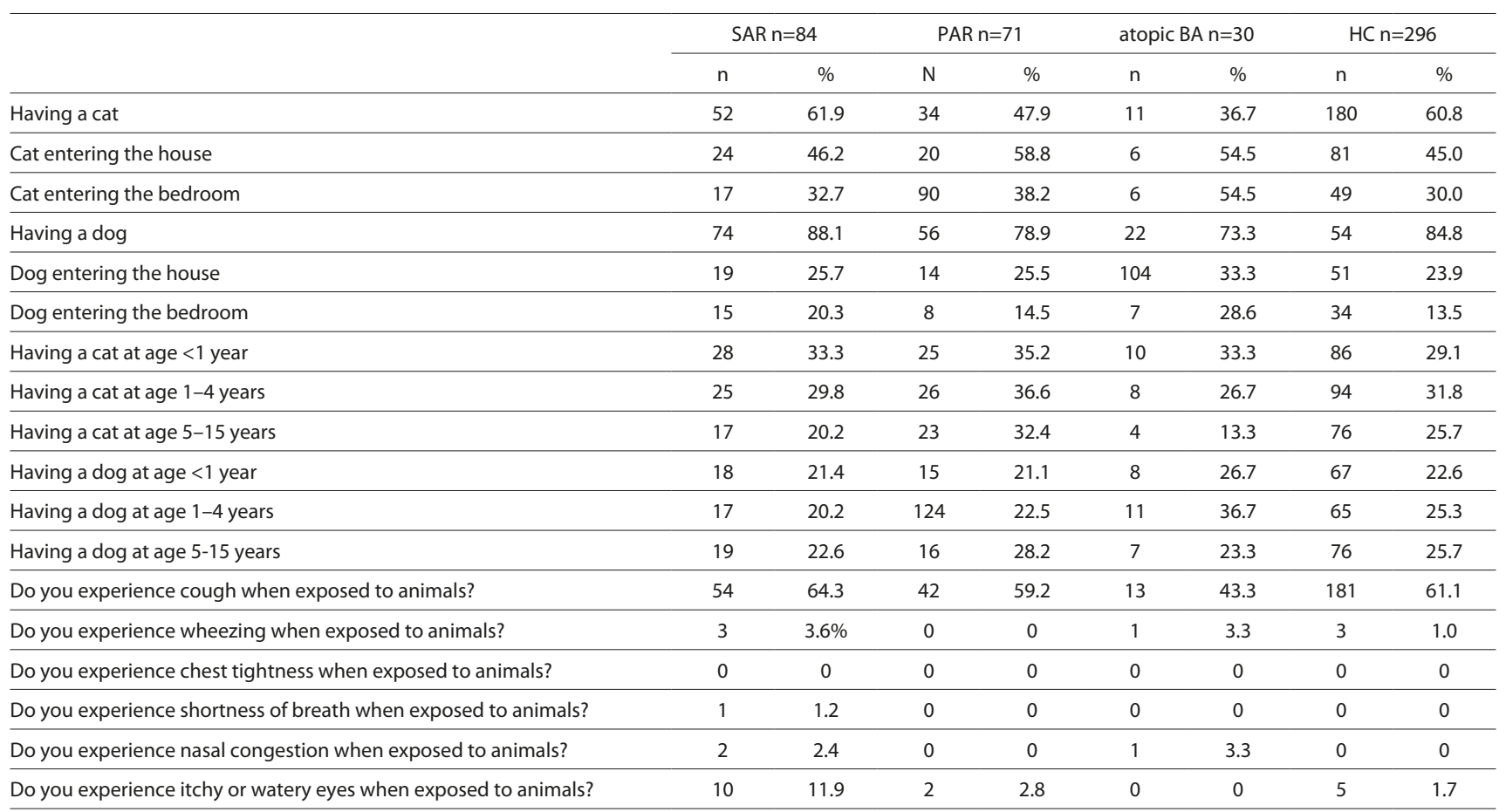

BA - bronchial asthma; HC - healthy controls; PAR - perennial allergic rhinitis; SAR - seasonal allergic rhinitis

In contrast, considerably fewer rural residents reported their pets being allowed into the house/bedroom. Nearly $35 \%$ of respondents had had a cat at the age of $<1$ year, and fewer had had a dog. Almost a half of the respondents (SAR and BA subgroups) reported mild cough and wheezing following exposure to pets.

One of the factors determining the keeping of fur-bearing animals, both in the urban and rural areas, was the mean size of the living space. In the urban setting, a cat was kept by respondents with living space of $63.89 \mathrm{~m}^{2}$, whereas a lack of household cats were reported by respondents with a mean living space of $57.59 \mathrm{~m}^{2}(\mathrm{P}<0.001)$. A similar phenomenon was observed in rural areas: the mean living space of respondents who had a cat measured $105.4 \mathrm{~m}^{2}$, whereas the mean living space of those without a cat was $99.12 \mathrm{~m}^{2}(\mathrm{P}<0.001)$. In urban settings, mothers who smoked 5.12 cigarettes per day had more cats than those who smoked 4.27 and did not have a cat $(\mathrm{P}<0.001)$. In rural settings, there were no statistically significant differences.

A similar relationship between pet ownership and size of living space was observed with respect to dogs. Urban owners of dogs reported a greater mean living space: the mean living space of a household with a dog was $62.5 \mathrm{~m}^{2}$, whereas that of a household without a $\operatorname{dog}$ was $54 \mathrm{~m}^{2}(\mathrm{P}<0.001)$. This was consistent with the rural settings, where the mean living space size of respondents who owned a dog was $104.5 \mathrm{~m}^{2}$, while the mean size of households without a dog was $95.35 \mathrm{~m}^{2}$ $(\mathrm{P}<0.001)$

Dog owners living in urban areas smoked considerably more cigarettes (15.83 cigarettes/month, on average) in comparison to those who did not own a dog (14.15 cigarettes/month) ( $\mathrm{P}=$ 0.005). Moreover, within the same area, dog-owning mothers smoked considerably more at 5.75 cigarettes in comparison to dog-less mothers (who, on average, smoked 3.85 cigarettes) $(\mathrm{P}<0.001)$. Data collected from rural respondents showed no statistically significant differences in the number of cigarettes smoked and dog ownership.

The study groups did not differ significantly in the level of education of mothers or pet-owners $(\mathrm{P}>0.1)$. Another factor that did not produce significant differences between study groups was the number of people per household $(\mathrm{P}>0.1)$.

Positive skin-prick test results for cat and dog allergens in the study population. Out of the AR subgroup, urban residents demonstrated considerably higher rates of positive cat and dog allergen tests. The proportion of positive skinprick test results was higher in respondents with PAR, compared with those of SAR-affected individuals, with considerably higher rates of positive reaction to cat allergens (Fig. 1a, b, c, d).

This was consistent with the results in individuals diagnosed with BA, in whom higher rates of positive and most varied skin-prick test reactions were observed with cat allergens. Interestingly, the rural population of study subjects demonstrated considerably higher rates of positive skin-prick test reactions of 3-5 $\mathrm{mm}$ to dog allergens.

Household pets and the risk of allergy-related symptoms. Metropolitan respondents with BA who spent their time near fur-bearing animals demonstrated higher risk of cough (OR 1.921; CI 10-3.36; P=0.02) (Figs. 5-6). Moreover, the presence of fur-bearing animals, including dogs, in the household increased the risk of developing BA (OR 1.45; CI 1.14$2.08 ; \mathrm{P}<0.05)$ and more than twice as often predisposed to wheezing in the BA subgroup (OR 2.60; CI 1.22-5.54; $\mathrm{P}=0.01$ ). The presence of fur-bearing animals around individuals with PAR increased the risk of nasal symptoms (OR 2.13; CI $1.36-3.33 ; \mathrm{P}<0.05)$, and the presence of a cat prior to age 1 year reduced the risk of developing PAR (OR 0.74; CI 0.56-0.97; $\mathrm{P}=0.02$ ). 
a)
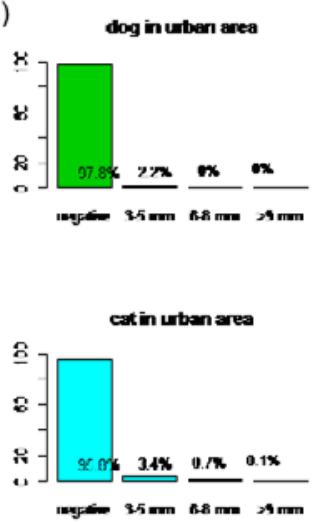

c)

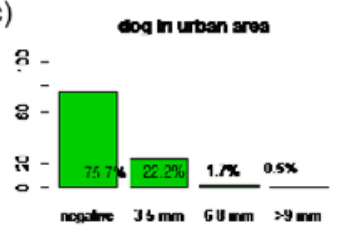

catin urban wrea

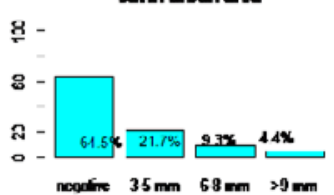

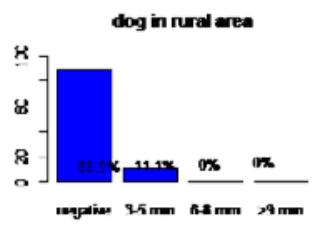
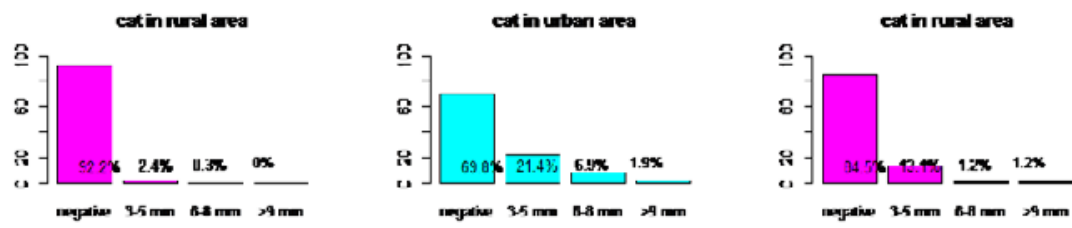

d)
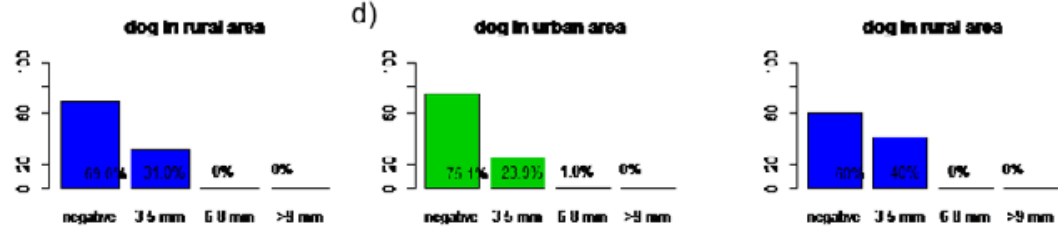

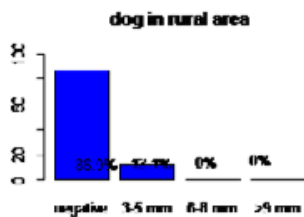

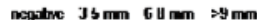
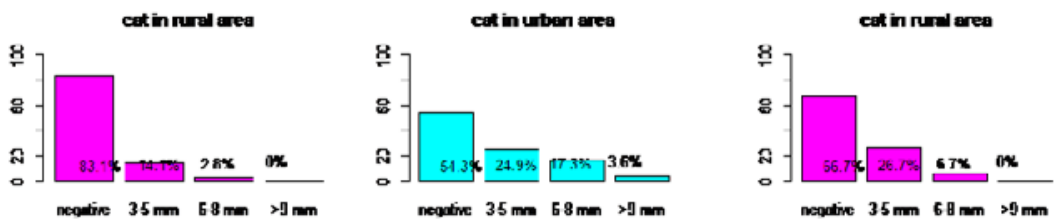

Figure 1. Skin prick test in the study group

a) Allergy rates for dog and cat allergens based on skin-prick tests in the healthy population.

b) Allergy rates for dog and cat allergens based on skin-prick tests in the evaluated population with seasonal allergic rhinitis (SAR).

c) Allergy rates for dog and cat allergens based on skin-prick tests in the evaluated population with perenniall allergic rhinitis (PAR)

d) Allergy rates for dog and cat allergens based on skin-prick tests in the evaluated population with atopic bronchial asthma (BA).

In rural areas, the presence of a $\operatorname{dog}(\mathrm{OR} 0.21$; CI 0.06-0.73; $\mathrm{P}=0.01$ ), especially in childhood (OR 0.29; CI 0.10-0.81; $\mathrm{P}=0.01)$ or a $\operatorname{dog}(\mathrm{OR} 0.37$; CI $0.17-0.80 ; \mathrm{P}<0.01)$, had a preventive effect against developing BA. This is also true in the group diagnosed with $\mathrm{AR}$, where a dog had a protective effect against the development of PAR (OR 0.58; CI 0.35-0.95; $\mathrm{P}<0.05)$.

\section{DISCUSSION}

Allergy to fur-bearing animals is a serious challenge for instituting preventive and therapeutic measures due to the high prevalence of fur-bearing pets, and the ease with which their allergens can be transferred to public facilities, such as nurseries, schools, pre-schools, means of transportation, hospitals, and houses [9]. The mean proportion of Polish households with a cat is $44 \%$ and with a dog $-83 \%$ of the general population [10]. These proportions of pet types are reflected in the proportions of pet owners in the allergic population, with more respondents with SAR, PAR, and BA owning a dog, in urban areas $27.4 \%, 26.6 \%$, and $35.5 \%$, respectively, and in rural areas $-88.1 \%, 78.9 \%$ and $73.3 \%$, respectively.

The factors that determined an increased likelihood of having a pet included larger living space and the number of cigarettes smoked by pet owners/mothers, which was observed especially in urban areas. These findings were consistent with those by Almqvist et al. who in their questionnaire-based study conducted in parents of a group of 4,089 children, demonstrated significantly higher rates of pets in households with a low social status, and in the case of mothers who smoked [11]. The literature on the subject does not clearly indicate a significant correlation between a bigger living space and the likelihood of having household pets. However, this correlation may be due to a less restrictive environment and greater living comfort.

The propagation of fur-bearing animal allergens is another problem. Moghtader et al. assessed allergen levels in dust samples collected from the kitchen and bedroom with an enzyme-linked immunosorbent assay (ELISA). The authors reported that the dust samples collected from 35 households of children with BA contained, apart from house dust mite and cockroach allergens, significantly higher levels of cat allergens in the bedroom (5.3 \pm 5.58$)$ vs. the kitchen $(1.2 \pm 3.65)$. Moreover, $94 \%$ of households had detectable levels of cat allergens, which the authors explained was to due to allergen transfer and the large number of undomesticated cats in the evaluated region [12]. These findings were consistent with the results of another prospective study by Kanchongkittiphon et al. conducted at 4 preschools and 17 elementary schools, evaluating dust samples collected from desktops. The study 
showed the presence of cat allergens in $93.3 \%$ of preschool dust samples and in $71.4 \%$ of school dust samples. Dog allergens were detected in $53.3 \%$ and $95.2 \%$ of preschool and school dust samples, respectively. For comparison, $53.3 \%$ and $77.8 \%$ dust samples collected from the floor in preschools and schools contained cat allergens, whereas dog allergens were present in $53.3 \%$ and $33.3 \%$ of floor dust samples, respectively [13]. Weiler et al. who collected samples from 57 households in western Montana (USA) demonstrated that the most common allergen was canine (Can $\mathrm{f} \mathrm{1)}$ ) and the second most common allergen was feline (Fel d 1), with the latter detected in 47 out of 57 evaluated households. Interestingly, only 21 households reported having a dog and 13 households reported having a cat, which emphasizes the importance of allergen transport into residences without a cat or a dog [14].

The environmental differences between urban vs. rural place of residence have a measurable impact not only on allergen prevalence but also on the proportion of residents sensitized to fur-bearing animals. Wardzyńska et al. evaluated the levels of allergens collected from 404 school-age children in the centre of Łódź (Poland) and 2 schoolchildren from a rural county (141 urban and 191 rural households), at the same time assessing the indoor environment of these households. The vast majority of children from rural areas $(n=152)$ lived in single-family houses (brick and concrete block construction), while only 7 lived in multiple-family households; children from urban areas lived in brick $(n=72)$ and concrete block houses $(n=45)$.

Samples collected from rural area households showed significantly higher levels of cat and dog allergens, with higher allergen levels present in mattresses than on the floor. Urban area samples showed only higher levels of dog allergens in mattresses vs. carpets. The mean levels of cat allergens in mattresses from rural households were considerably lower than those from urban households $(0.43 \mathrm{mcg} / \mathrm{g}$; $0.28-0.64$ vs. $0.61 \mathrm{mcg} / \mathrm{g} ; 0.27-0.84 ; \mathrm{P}=0.002)$, whereas dust samples collected from carpets showed higher levels of cat allergens in rural areas $(0.45 \mathrm{mcg} / \mathrm{g} ; 0.24-0.78 \mathrm{vs}$. urban areas $-0.32 \mathrm{mcg} / \mathrm{g} ; 0.12-0.75 ; \mathrm{P}=0.016)$. Urban households with pets (12 households had cats, 57 households had dogs) demonstrated higher allergen levels than households without pets. Interestingly, the levels of feline allergens in mattresses and carpets of children with AR were higher than those of healthy volunteers (allergens in mattresses $0.71 \mathrm{ng} / \mathrm{g}$ (0.46-0.93) vs. $0.55 \mathrm{ng} / \mathrm{g}(0.19-0.8)$, respectively $(\mathrm{P}=0.015)$, in carpets $0.46 \mathrm{ng} / \mathrm{g}(0.18-0.96)$ vs. $0.25 \mathrm{ng} / \mathrm{g}(0.09-0.69)$, respectively $(\mathrm{P}=0.027)$ [15].

Estimates by Kuprys-Lipińska et al. showed the proportion of positive skin-prick tests to cat allergens to be significantly higher in the urban population vs. the rural population $(9.3 \%$ and $5.4 \%$ of the general study population, respectively) [16]. This is consistent with the presented findings that show aconsiderably higher proportion and severity of allergies detected with skin-prick tests in urban residents. Contrary to the preventive effects of having a cat or a dog observed in rural areas, in the urban populations having a pet seems to increase the risk of symptoms, especially bronchial symptoms; cough (OR 1.921; CI 10-3.36; P=0.02). Dog owners with BA had a more than double risk of developing wheezing (OR 2.60; CI 1.22-5.54; $\mathrm{P}=0.01$ ), whereas having a cat before age 1 year alone reduces the risk of developing PAR (OR 0.74; CI $0.56-0.97 ; \mathrm{P}=0.02$ ).
Attempting to determine the factors responsible for BA, Baldaçara et al. demonstrated significant effects of not only Cesarean section (OR 3.367; $\mathrm{P}=0.019$ ), but also family history of allergies (OR 5.833; $\mathrm{P}=0.002$ ), maternal diagnosis of BA (OR 8.077; $\mathrm{P}=0.048$ ), and exposure to pets (OR 3.600; $\mathrm{P}=0.012)$. The proportion of respondents with allergies to cats and dogs was $28.7 \%$ and $21.3 \%$, respectively. Pet allergens were classified as the most common allergy-promoting factors right next to Dermatophagoides pteronyssinus (34\%) and Dermatophagoides farinae (19.1\%) allergens [17]. Therefore, pet-derived allergens seem to play a role in the development of bronchial asthma. Moreover, a considerably greater proportion of urban respondents reported allowing cats or dogs to enter the bedroom/house, which is likely to be due to living space limitations (lack of yards/gardens around tenement housing in urban areas). In addition, a significantly higher proportion of rural inhabitants reported the presence of a cat; $61.9 \%$ of respondents with SAR, $47.9 \%$ of respondents with PAR, and $36.7 \%$ of respondents with BA, fur-bearing animals were also present in a higher proportion of urban residents, both before age 1 and between ages 1 and 5 years. Interestingly, having fur-bearing pets in rural areas was associated with a distinct preventive effect, despite the recorded positive skin-prick test results.

A cohort study by Schoos et al. assessed the effect of perinatal exposure to fur-bearing animals in a group of 399 children with the use of skin-prick tests and the levels of specific IgE against feline and canine allergens at the ages of 6 months and 1.5, 5, 6, and 13 years. Dust samples were collected at the third trimester of pregnancy and evaluated for cat and dog allergens. No causative relationship was demonstrated between having a dog or a cat in the perinatal period and developing an allergy or rhinitis in childhood [18].

A cohort study by Herrant et al. conducted with a standardized ISAAC questionnaire in a group of 321 children $(<1$ year, 107 aged $1-5$ years, 105 aged $5-10$ years, and 93 aged $10-15$ years) to assess risk factors of BA, atopic dermatitis (AD), and allergic conjunctivitis demonstrated a significant correlation between the presence of a cat or a dog in the household and increased risk of BA (cat: OR 5.3; 95\% CI 1.49-18.8; $\mathrm{P}=0.01$; dog: OR 2.28, 95\% CI 1.26-4.11, $\mathrm{P}=0.006)$. However, the presence of a cat in the household was associated with lower risk of AD (OR 0.5; 95\% CI 0.25-0.99; $\mathrm{P}=0.048$ ). Exposure to a dog was associated with a higher risk of developing BA only in younger children (OR 3.50; 95\% CI 1.35-9.09; $\mathrm{P}=0.01$ ) [19].

\section{CONCLUSION}

Having a fur-bearing pet in a rural setting has a preventive effect, in contrast to urban areas, where pets exacerbate the symptoms, especially symptoms of BA. In urban settings, cat exposure prior to age 1 alone has a preventive effect against developing AR.

\section{REFERENCES}

1. http://www.worldallergy.org/index.php (access: 15.05.2016)

2. Samoliński B, Raciborski F, Lipiec A, Tomaszewska A, Krzych-Fałta E, et al. Epidemiologia Chorób Alergicznych w Polsce. Alergol Pol. 2014; 1: 10-18. 
3. Lødrup Carlsen KC, Roll S, Carlsen KH, Mowinckel P, Wijga AH, Brunekreef B, et al. Does Pet Ownership in Infancy Lead to Asthma or Allergy at School Age? Pooled Analysis of Individual Participant Data from 11 European Birth Cohorts. PLoS One. 2012; 7(8): e43214. doi: 10.1371/journal.pone.0043214.

4. Papadopoulos NG, Agache I, Bavbek S, Bilo BM, Braido F, Cardona V, et al. Research needs in allergy: an EAACI position paper, in collaboration with EFA. Clin Transl Allergy. 2012; 2(1): 21.

5. Strahan DP. Hay fever, hygiene, and household size. BMJ. 1989 Noy 18; 299(6710): 1259-60.

6. Shaheen SO, Aaby P, Hall AJ, Barker DJ, Heyes CB, Shiell AW, et al. Measles and atopy in Guinea-Bissau. Lancet. 1996 Jun 29; 347(9018): 1792-6.

7. Perkin MR, Strachan DP. Which aspects of the farming lifestyle explain the inverse association with childhood allergy? J Allergy Clin Immunol. 2006; Jun; 117(6): 1374-1381.

8. Luczynska CM, Li Y, Chapman MD, Platts-Mills TA. Airbone concentrations and particle size distribution off allergen derived from domestic cats (Felis domesticus). Measurments using cascade impactor, liquid impinger, and a two-site monoclonal antibody assay for Fel d1. Am Rev Respir Dis. 1990 Feb; 141(2): 361-7.

9. 8a. The R Project for statistical computing: https://www.r-project.org/

10. Bousquet J, Khalataev N, Alvaro A, Denburg J, Fokkens W, Togias A, et al. Allergic Rhinitis and its Impact on Asthma (ARIA) 2008. Alergia Astma Immunol Klin. 2008; 13(1): 3-39.

11. Sokołowska-Ukleja N, Bartuzi Z. Epidemiologia i przebieg naturalny alergii na zwierzeta futerkowe. Alergol Pol. 2016: 32-38.

12. Almqvist C, EgmarAC, van Hage-Hamsten M, Berglind N, Pershagen G, Norvdvall SL, et al. Hederity, pet ownership, and confounding control in a population-based birth cohort. J Allergy Clin Immunol. 2003; 111(4): 800-806.
13. Moghtaderi M, Farjadian S, Fereidouni M, Nasiri M, Nejat A. Indoor Dust Allergen Levels in the Homes of Patients with Childhood Asthma: An Experience From Southwestern Iran. Iran J Allergy Asthma Immunol. 2016; Apr; 15(2): 132-137.

14. Kanchongkittiphon W, Sheehan WJ, Friedlander J, Chapman MD, King E-M, Martirosyan K, et al. Allergens on Desktop Surfaces in Preschools and Elementary Schools of Urban Children with Asthma. Allergy. 2014; Jul; 69(7): 960-963. doi: 10.1111/all.12384.

15. Weiler E, Semmens E, Noonan C, Cady C, Ward T. Dust Allergens within Rural Northern Rocky Mountain Residences Jacobs J Allergy Immunol. 2015; Jan 23; 1(2): 1-6.

16. Wardzyńska A, Majkowska-Wojciechowska B, Pełka J, Korzon L, Kaczała M, Jarzębska M, et al. Association of House Dust Allergen Concentrations With Residential Conditions in City and in Rural Houses World Allergy Organ J. 2012 Feb; 5(2): 22-27. 10.1097/WOX. doi: 0b013e3182447fa8.

17. Kupryś-Lipińska I, Elgalal A, Kuna P. Urban-rural differences in the prevalence of atopic diseases in the general population in Lodz Province (Poland). Post Dermatol Alergol Pol. 2009; XXVI(5): 249-256.

18. Baldaçara RP, Fernandes Mde F, Baldaçara L, Aun WT, Mello JF, Pires MC. Prevalence of allergen sensitization, most important allergens and factors associated with atopy in children. Sao Paulo Med J. 2013; 131(5): 301-308. doi: 10.1590/1516-31802013.1315502.

19. Schoos AM, Chawes BL, Jelding-Dannemand E, Elfman LB, Bisgaard H. Early indoor aeroallergen exposure is not associated with development of sensitization or allergic rhinitis in high-risk children. Allergy. 2016; Feb 2. doi: 10.1111/all.12853.

20. Herrant H, Loucoubar Ch, Boufkhed S, Bassène H, Diene Sarr H, Baril $\mathrm{L}$, et al. Risk factors associated with asthma, atopic dermatitis and rhinoconjunctivitis in a rural Senegalese cohohort. Allergy Asthma Clin Immunol. 2015; 11(1): 24. doi: 10.1186/s13223-015-0090-0. 